\title{
Biogas production from Macrocystis pyrifera biomass in seawater system
}

\author{
Xiaolei Fan ${ }^{a}$, Rongbo Guo ${ }^{a}, *$, Xianzheng Yuan ${ }^{a}$, Yanling Qiu ${ }^{a}$, Zhiman Yang ${ }^{a}$, Fei Wang ${ }^{a, c}$, \\ Mengting Sun ${ }^{\mathrm{a}, \mathrm{c}}$, Xiaoxian Zhao ${ }^{\mathrm{b}}$
}

a Shandong Industrial Engineering Laboratory of Biogas Production E Utilization, Qingdao Institute of Bioenergy and Bioprocess Technology, Chinese Academy of Sciences, Songling Road 189, Qingdao 2661 01, China

${ }^{\mathrm{b}}$ College of Chemical Science and Engineering, Qingdao University, Qingdao 266071, China

${ }^{\mathrm{C}}$ University of Chinese Academy of Science, Beijing 10049, China

\section{H I G H L I G H T S}

- Raw seaweed was converted to biomethane efficiently in real seawater system.

- Microbe in the littoral sediment showed the higher methanogenesis activity.

- Microbial communities in thalassic biogas production system were first studied.

\section{A R T I C L E I N F O}

\section{Article history:}

Received 24 June 2015

Received in revised form 28 August 2015

Accepted 29 August 2015

Available online 1 September 2015

\section{Keywords:}

Anaerobic fermentation

Marine sediments

Macrocystis pyrifera

Methanogenetic pathway

Sulfate

\begin{abstract}
A B S T R A C T
Marine sediments from littoral and sublittoral location were evaluated as inocula for methane production from anaerobic fermentation of Macrocystis pyrifera in seawater system. Littoral sediment showed the higher methanogenetic activity from acetate and resulted in a higher biomethane yield of $217.1 \pm 2.4 \mathrm{~mL} / \mathrm{g}$-VS, which was comparable with that reported in freshwater system with desalted seaweeds. With $0.8 \mathrm{mM}$ sodium molybdate added, both the maximal methane yield and concentration increased while the lag-time was greatly shortened, suggesting that sulfate was one of the major inhibitors. Microbial community analysis revealed that degradation of $M$. pyrifera needed cooperation of very complex microbial populations. Hydrogenotrophic methanogens had an absolute dominance in distribution compared with the acetotrophic ones, indicating syntrophic acetate oxidation coupled to hydrogenotrophic methanogenesis might play important roles in the thalassic anaerobic fermentation system. These results clearly showed that biomethane production of raw seaweeds in seawater system was feasible.
\end{abstract}

(c) 2015 Elsevier Ltd. All rights reserved.

\section{Introduction}

Marine macroalgae was known as "3rd generation biomass feedstock" for biofuel production due to its high productivity rates, negligible lignin content and higher $\mathrm{CO}_{2}$ mitigation effects compared to terrestrial biomass (Roesijadi et al., 2010). It was believed to be a promising alternative biomass feedstock for the production of sustainable bioenergy and biomaterials. Therefore, biogas production from anaerobic fermentation of seaweeds is attracting more and more attention all over the world.

However, several factors would inhibit the utilization of seaweeds biomass for biogas production (Debowski et al., 2013; Ward et al., 2014). High salinity was one of the major inhibitors. The high salt content of seaweed biomass could prevent anaerobic

\footnotetext{
* Corresponding author. Tel./fax: +86 53280662708.

E-mail address: guorb@qibebt.ac.cn (R. Guo).
}

degradation using conventional terrestrial activated sludge as inoculum (Demirbas, 2010), especially in thermophilic anaerobic fermentation (Chen et al., 2008; Ghosh et al., 1981). In addition, the superficial seawater over the fresh algae also brought a lot of sodium salt into the fermentation system. High $\mathrm{Na}^{+}$concentration was proved toxic to terrestrial microbial communities, especially to methanogens (Chen et al., 2003; Jard et al., 2012). Therefore, the removal of salt from the seaweeds was necessary for a steady process using terrestrial inoculum, though it might be freshwater-wasting and expensive.

Since most abundant seaweeds are produced in island or seashore communities where freshwater supply is scarce, efforts have been made to investigate the feasibility for biogas production in seawater system. In 1984, Schramm et al. reported that marine sediment microbe could produce methane from seaweeds at brackish salinity (with a salinity of 15\%o) (Schramm and Lehnberg, 1984). Marquez et al confirmed this again by producing 
biogas from the sea wrack biomass in a seawater system using marine sediment mixture from mangrove and sea grass mudflat as inoculum. They also found that marine inocula led to higher methane yield compared to terrestrial ones (Marquez et al., 2013). These results proved that marine sediment itself possessed the microbial communities for hydrolysis, acidogenesis, acetogenesis and methanogenesis (Miura et al., 2014). All these works shed new light on the energy resources of island and seashore communities. However, the $\mathrm{CH}_{4}$ yield in marine anaerobic fermentation system was much lower than the estimated value (Marquez et al., 2013). Since there were great differences among microbial communities from different marine habitats (Liu et al., 2014), it was speculated that marine sediment from quite different ecosystems, such as sublittoral marine oil and gas field or littoral shellfish culture zone, might have different biomethane production potential.

In this context, this study aimed (1) to evaluate the biomethane production potential of raw seaweeds in real seawater system using marine sediment samples from quite different habitat as inocula and (2) to look into the underlying microbial communities and methanogenetic pathways in thalassic biogas production system of Macrocystis pyrifera using marine sediments. For this, batch tests were operated at a mesophilic temperature using raw M. pyrifera biomass as the sole substrate in seawater system. Two different sediment samples from quite different habitat, one from littoral shellfish culture zone (MSI) and another from sublittoral location in Arabic ocean where are rich in oil and gas field (MSII), were used as inocula. The methanogenetic pathways were studied by specific methanogenetic activity evaluation using different carbon resources associated with microbial community analysis. To the best of the authors' knowledge, the present study is the first to look into the underlying microbial communities and methanogenetic pathways in thalassic biogas production system of M. pyrifera using marine sediments inocula. This study provides fundamental information that can help address the knowledge gap in understanding seaweed anaerobic fermentation.

\section{Methods}

\subsection{Seaweeds and marine sediments}

The M. pyrifera biomass was collected from Zhangzi Island, Dalian, China and was sun-dried for storage. Before use, the seaweeds was milled to a size of about $1 \mathrm{~cm}$. Marine sediments I (MSI) was obtained from Jiaozhou Bay in shellfish culture zone, China and marine sediments II (MSII) was obtained from Arabian sea where are rich in oil and gas field.

\subsection{Proximate composition}

Proximate composition of $M$. pyrifera such as moisture, total solids, volatile solids, ash, crude fat (CF, Soxhlet method), crude protein (CP, Kjeldahl method) and crude carbonhydrate (CC) (including crude fiber (Weende method) and $\mathrm{N}$-free extract (Marquez et al., 2013)) content were measured using standard procedure. The theoretical methane potential (TMP) was calculated use the formula (Marquez et al., 2013): TMP $=\{[(0.49 \mathrm{~L} / \mathrm{g}-\mathrm{VS}) \times$ (Hutner et al. $)]+[(0.85 \mathrm{~L} / \mathrm{G}-\mathrm{VS}) \times(\mathrm{CF})+[(0.395 \mathrm{~L} / \mathrm{g}-\mathrm{VS}) \times(\mathrm{CC})]\} /$ volatile solids $(\mathrm{g})$.

\subsection{Biogas fermentation process}

$500 \mathrm{~mL}$ serum bottles sealed with butyl rubbers were applied in all the experiments. $1.75 \mathrm{~g}$ milled seaweeds were used as feedstock. The working volume was $100 \mathrm{~mL}$ and flushed with $\mathrm{N}_{2}$ for $10 \mathrm{~min}$. Three replicates were conducted for each anaerobic degradation set-up. The set-ups made were, MSI (with marine sediment I as inoculum) and MSII (with marine sediment II as inoculum) set-ups. The inocula were pre-incubated for 3 days until no obvious methane was produced. The ISRs (inoculum substrate ratio) were adjusted to $1: 1$. Table 1 summarized all the contents of the algal feedstock and marine sediments. Sterilized seawater was used as the liquid medium of MSI and MSII set-ups. Blank controls were set without adding the algal feedstock. Biogas digesters were connected to a $2 \mathrm{~L}$ bottle water displacer where the biogas produced was trapped by displacing saturated $\mathrm{NaCl}$ solution. The volume of displaced saturated $\mathrm{NaCl}$ solution was measured as the volume of the biogas produced. The salinity and $\mathrm{pH}$ were measured using ATAGO hand-held refractometer and portable digital $\mathrm{pH}$ meter, respectively. The digesters were incubated at $37^{\circ} \mathrm{C}$ with constant shaking at $150 \mathrm{rpm}$.

VFA, methane and hydrogen were measured by Gas Chromatograph as described previously (Yuan et al., 2011). $\mathrm{H}_{2} \mathrm{~S}$ concentration was measured using $\mathrm{H}_{2} \mathrm{~S}$ gas detection tubes (Shanghai Yudong electronic technology co., LTD. China). Cumulative biogas and methane production curves were fitted to the modified Gompertz equation (Huilinir et al., 2014):

$y=A \cdot \exp \left\{-\exp \left[B \cdot e \cdot\left(x_{c}-x\right) / A+1\right]\right\}$

where A represents potential methane or biogas production $(\mathrm{mL} / \mathrm{g})$, $B$ is the maximum rate of methane or biogas production $(\mathrm{mL} / \mathrm{g} / \mathrm{h}), \mathrm{x}_{\mathrm{c}}$ is the lag time phase (d), $y$ is the methane accumulated at time $t, t$ is the measured time (d), and e is the base of the natural logarithms (2.718282).

\subsection{Methanogenetic activity determination}

Methanogenetic activity determination was applied in $60 \mathrm{~mL}$ serum bottles sealed with butyl rubbers with $20 \mathrm{~mL}$ working volume. $20 \mathrm{~mL}$ of the sediments were rinsed with filtrated phosphate buffer three times to get rid of the solute organic substrates and then were resuspended in $20 \mathrm{~mL}$ phosphate buffer. $\mathrm{H}_{2} / \mathrm{CO}_{2}$ $(80: 20 \mathrm{v} / \mathrm{v}, 0.2 \mathrm{MPa})$ and $5 \mathrm{mM}$ different substrates (formate, methanol, acetate, propionate, butyrate and ethanol) were added as carbon resources respectively. Blank controls were set without the added carbon resources.

\subsection{DNA extraction, PCR amplification, 16s rRNA library sequencing and analysis}

The samples were prepared after the biomethane production finished. Total genome DNA was extracted using CTAB/SDS method. Bacterial primer pairs (515f/806r) for V4 region of $16 \mathrm{~S}$ rRNA (Peiffer et al., 2013) together with the barcode were used to amplify the $16 \mathrm{~S}$ rRNA genes. The PCR reactions were carried out in $30 \mu \mathrm{L}$ reactions with $15 \mu \mathrm{L}$ of Phusion $^{\circledR}$ High-Fidelity PCR

Table 1

The proximate values of Macrocystis pyrifera and inocula. FM, fresh matter; DM, dry matter.

\begin{tabular}{llll}
\hline Proximate tests & Value (\%) & & \\
\cline { 2 - 4 } & $\begin{array}{l}\text { Macrocystis } \\
\text { pyrifera }\end{array}$ & $\begin{array}{l}\text { Marine } \\
\text { sediment I }\end{array}$ & $\begin{array}{l}\text { Marine } \\
\text { sediment II }\end{array}$ \\
\hline Moisture(FW) & 11.3 & 51.5 & 59.4 \\
Total solids (FW) & 88.7 & 48.5 & 40.6 \\
Volatile solid (DW) & 64.3 & 4.9 & 14.4 \\
Ash (DW) & 35.7 & 95.1 & 85.6 \\
Crude fat (DW) & 8.3 & & \\
Crude protein (DW) & 12.2 & & \\
Crude hydrocarbon (DW) & 40.6 & & \\
\hline
\end{tabular}


Master Mix (New England Biolabs), $0.2 \mu \mathrm{M}$ of forward and reverse primers, and about $10 \mathrm{ng}$ DNA template. Thermal cycling consisted of initial denaturation at $98^{\circ} \mathrm{C}$ for $1 \mathrm{~min}$, followed by 30 cycles of denaturation at $98{ }^{\circ} \mathrm{C}$ for $10 \mathrm{~s}$, annealing at $50{ }^{\circ} \mathrm{C}$ for $30 \mathrm{~s}$, elongation at $72{ }^{\circ} \mathrm{C}$ for $60 \mathrm{~s}$, and elongation at $72{ }^{\circ} \mathrm{C}$ for 5 min finally.

PCR products were purified with GeneJET Gel Extraction Kit (Thermo Scientific). Sequencing libraries were generated using NEB Next ${ }^{\circledR}$ Ultra $^{\text {TM }}$ DNA Library Prep Kit. After quality assessment, the library was sequenced on an Illumina MiSeq platform (NEB, USA).

Raw tags were produced from the merged paried-end reads using FLASH (Magoc and Salzberg, 2011). To obtain clean tags, the low quality sequences and chimeras were filtered, trimmed and removed using the Quantitative Insights into Microbial Ecology (QIIME software v1.3.0) pipeline and UCHIME Algorithm. FASTAQ formatted sequences of clean tags have been submitted to the GeneBank Sequence Read Archive with accession No. SRR2001625. The clean tags were clustered into operational taxonomic units (OTUs) by setting a 0.03 distance limit using the Uparse program. The taxonomy of OTU representative sequences were phylogenetically assigned to taxonomic classifications by RDP Classifier with a confidence threshold of $80 \%$. Rarefaction curves were obtained using MOTHUR program (http://www.mothur.org/wiki/Main_ Page).

\section{Results and discussion}

\subsection{Biogas production performance of M. pyrifera using different marine sediments as inocula}

In this study, the biogas production performance of raw M. pyrifera in real seawater system using marine sediment inocula from quite different habitat was investigated. The results were shown in Fig. 1. Biogas was initially produced after 2 and 7 days of fermentation for MSI and MSII set-ups, respectively (Table 2). Lag phase during the start of biogas production could be due to limitation on bioavailability of nutrient substrate for microbial consumption (Angenent et al., 2002; Marquez et al., 2013). The MSI set-ups had the shorter lag phase. Since the sampling site is in shellfish culture zone, where the sediments were rich in rotten algal bait and microflora degrading algae, it was thought that microflora in MSI could utilize $M$. pyrifera biomass immediately. On the other hand, MSII sampling site is in the sublittoral sea with little algal biomass,

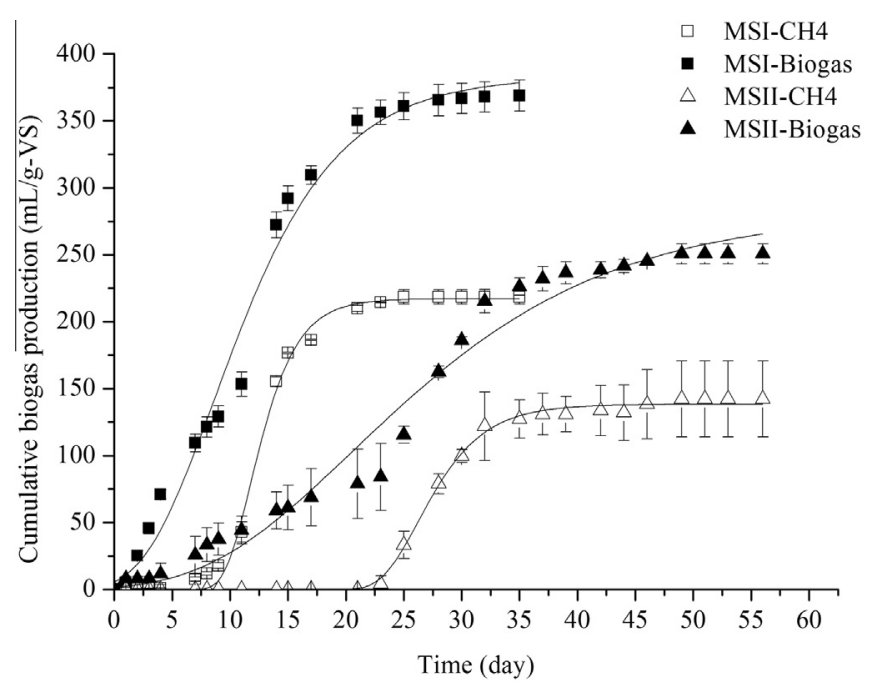

Fig. 1. Biomethane and biogas production of MSI and MSI set-ups.
Table 2

Fitting parameters of biogas production results. A, Maximal yield. B, Maximal evolving rate. $\mathrm{X}_{\mathrm{c}}$, Lag time

\begin{tabular}{lrrrrl}
$\begin{array}{l}\text { Experimental } \\
\text { set-ups }\end{array}$ & $\mathrm{A}(\mathrm{ml} / \mathrm{g}-\mathrm{VS})$ & $\mathrm{B}(\mathrm{ml} / \mathrm{g}-\mathrm{VS} / \mathrm{d})$ & $X_{c}(\mathrm{~d})$ & $R^{2}$ & $\begin{array}{l}\mathrm{CH} 4 \\
\text { conversion } \\
\text { efficiency } \\
(\%)\end{array}$ \\
\hline MSI-CH4 & $217.1 \pm 2.4$ & $35.4 \pm 2.4$ & $9.5 \pm 0.2$ & 0.996 & 48.0 \\
MSI-Biogas & $383.1 \pm 9.7$ & $23.5 \pm 1.8$ & $2.6 \pm 0.6$ & 0.986 & \\
MSII-CH4 & $138.3 \pm 1.0$ & $16.0 \pm 0.7$ & $23.1 \pm 0.2$ & 0.998 & 30.6 \\
MSII-Biogas & $282.4 \pm 13.3$ & $8.2 \pm 0.6$ & $8.0 \pm 1.2$ & 0.976 & \\
\hline
\end{tabular}

and it would take longer time for the accumulation of anaerobic microflora that could degrade $M$. pyrifera biomass.

Methane was initially produced on the 7th and 16th day after the biogas evolving in MSI and MSII set-ups, respectively. The maximal methane yield was obtained in MSI set-ups and reached about $217.1 \pm 2.4 \mathrm{~mL} / \mathrm{g}$-VS. It is about $60 \%$ higher than that in MSII setups. The average $\mathrm{CH}_{4}$ content of MSI set-ups (56.7\%) is also higher than that of MSII set-ups (43.9\%). It seemed that both the methane yield and the maximal methane production rate were quite different using different marine sediment inocula, indicating that screening of appropriate marine inoculum was necessary for the high $\mathrm{CH}_{4}$ yield. It is also the highest result in seawater anaerobic fermentation system with seaweeds as feedstock so far and even comparable to that obtained in previous reports of methane production from M. pyrifera (Ghosh et al., 1981) and other seaweeds (Hinks et al., 2013) at reduced salinity.

It should be noted that there was no detectable methane in the biogas during the initial several days, which was mainly consisted of $\mathrm{CO}_{2}$ and $\mathrm{H}_{2} \mathrm{~S}$ (more than $2500 \mathrm{ppm}$ ). Since the seawater was very rich in sulfate ( $\mathrm{S}$ concentration reached about $0.9 \mathrm{~g} / \mathrm{kg}$ ) and sulfatereducing bacteria (SRB) was also found in marine environment (Laanbroek and Veldkamp, 1982), the thalassic fermentation system offered favorable conditions for the multiplication of not only methanogens but also SRB. However, the duplication time of SRB was much shorter than methanogens (Medircio et al., 2007). In addition, SRB could outcompete methanogens in $\mathrm{H}_{2}$ and acetate utilization (Lovley et al., 1982; Oremland and Polcin, 1982), hence producing $\mathrm{H}_{2} \mathrm{~S}$ instead of $\mathrm{CH}_{4}$. To evaluate the inhibition of sulfate in seawater anaerobic fermentation systems and to quantify the biomethanation potential of $M$. pyrifera biomass using marine sediment inocula without SRB, sodium molybdate, a specific inhibitor of SRB (Marquez et al., 2013), was added to the acclimated MSI and MSII set-ups (using digestate in MSI and MSII set-ups as inoculum) to make the final concentration of $0.4 \mathrm{mM}$ and $0.8 \mathrm{mM}$. Similar results were found between MSI and MSII set-ups. Both methane yield and concentration increased with the sodium molybdate concentration (Table 3, Fig. 2). Compared with the control without the sodium molybdate, the maximal methane yield and concentration increased by $49.8-57.5 \%$ and $15.5-16.4 \%$, respectively. In addition, the lag-time was also greatly shortened by $45.2-51.1 \%$. So, it was speculated that SRB was first accumulated during the lag time, and the accumulated $\mathrm{H}_{2} \mathrm{~S}$ would inhibit methanogen growth thus further lengthened the lag-time and reduced the $\mathrm{CH}_{4}$ concentration in this study. SRB inhibition might be one of the major problems in practical application of thalassic biogas fermentation. Although transition-metal compounds including molybdate had a good effect on SRB inhibition, they were too costly for practical use and investigation on new economic technologies was still needed.

Sodium and potassium are two of the most soluble mental cations (consist about $90 \%$ of the mental cations) in the seawater anaerobic fermentation system in this study. The final soluble sodium concentration in both MSI and MSII set-ups was similar of about $12.0 \mathrm{~g} / \mathrm{L}$. The potassium concentration was $0.8 \mathrm{~g} / \mathrm{L}$ for 
Table 3

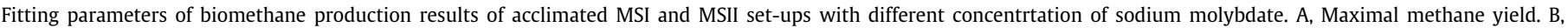
Maximal methane evolving rate. $X_{c}$, Lag time.

\begin{tabular}{|c|c|c|c|c|c|c|c|}
\hline Set-ups & $\mathrm{Na}_{2} \mathrm{MoO}_{4}(\mathrm{mM})$ & $\mathrm{A}(\mathrm{ml} / \mathrm{g}-\mathrm{VS})$ & $\mathrm{B}(\mathrm{ml} / \mathrm{g}-\mathrm{VS} / \mathrm{d})$ & $X_{c}(\mathrm{~d})$ & $R^{2}$ & $\mathrm{CH}_{4}$ content (\%) & CH4 conversion efficiency (\%) \\
\hline MSI & 0 & $183.5 \pm 1.4$ & $11.6 \pm 0.4$ & $4.4 \pm 0.2$ & 0.995 & $51.3 \pm 0.1$ & 40.6 \\
\hline MSI & 0.4 & $230.6 \pm 1.0$ & $13.3 \pm 0.2$ & $3.7 \pm 0.1$ & 0.998 & $59.2 \pm 0.2$ & 51.0 \\
\hline MSI & 0.8 & $284.4 \pm 0.8$ & $15.0 \pm 0.2$ & $1.8 \pm 0.1$ & 0.999 & $59.3 \pm 0.1$ & 62.9 \\
\hline MSII & 0 & $114.5 \pm 1.7$ & $7.5 \pm 0.4$ & $8.4 \pm 0.4$ & 0.994 & $47.6 \pm 0.3$ & 25.3 \\
\hline MSII & 0.4 & $140.8 \pm 1.3$ & $8.2 \pm 0.3$ & $4.6 \pm 0.3$ & 0.997 & $53.9 \pm 0.1$ & 30.9 \\
\hline MSII & 0.8 & $180.3 \pm 1.9$ & $11.7 \pm 0.5$ & $4.6 \pm 0.3$ & 0.996 & $55.4 \pm 0.2$ & 39.8 \\
\hline
\end{tabular}

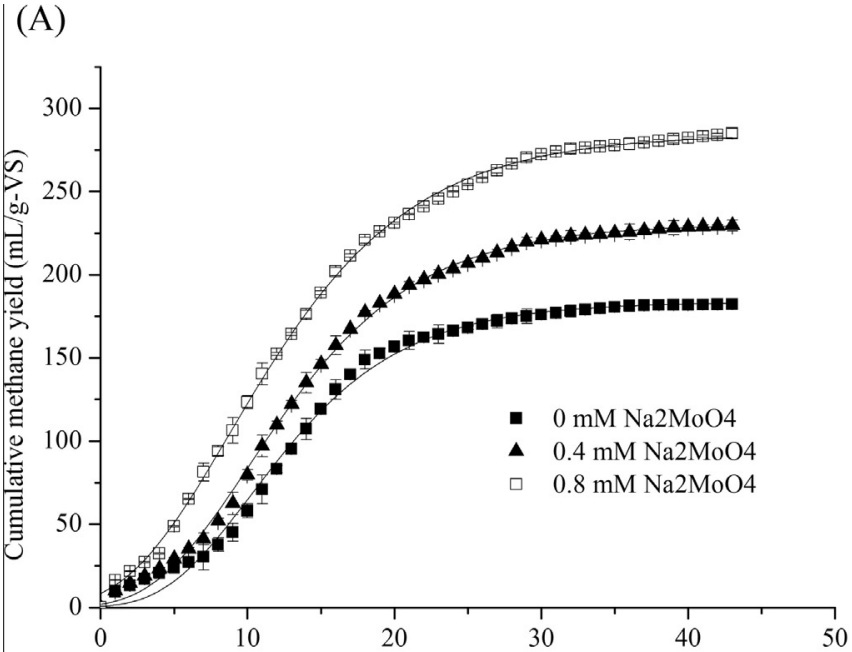

(B)

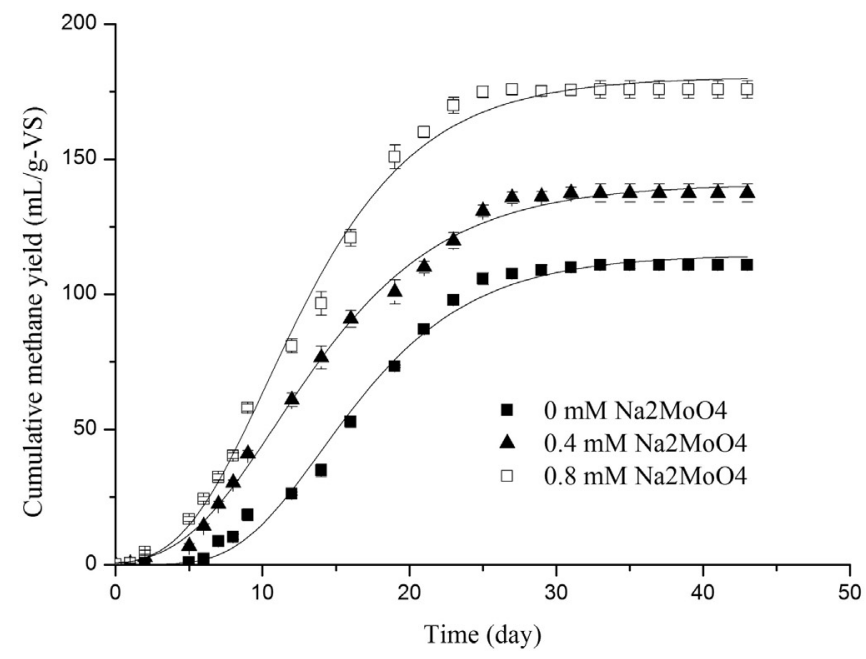

Fig. 2. Biomethane production of acclimated (A) MSI set-ups and (B) MSII set-ups with different concentrtation of sodium molybdate.

MSI and $0.7 \mathrm{~g} / \mathrm{L}$ for MSII. The toxic effect of potassium toxicity is rarely reported in the literature. It was ever observed that between $5.8 \mathrm{~g} / \mathrm{L}$ and $28.9 \mathrm{~g} / \mathrm{L}$ of $\mathrm{K}^{+}$caused $50 \%$ of inhibition of acetate utilizing methanogens (Chen et al., 2008). So, it was speculated that the potassium concentration would not cause the severe inhibition at the experimental substrate concentration. Depending on the batch assay conditions reported in literatures, sodium cation has been reported to cause moderate inhibition on methanogenic activity at $3.5-5.5 \mathrm{~g} / \mathrm{L}$ and severe inhibition at a sodium concentration of $8 \mathrm{~g} / \mathrm{L}$ (Chen et al., 2008). However, the $\mathrm{IC}_{50}$ of methanogens for sodium inhibition would be increased by long-term adaptation, especially in mixed methanogen culture (Chen et al., 2008).

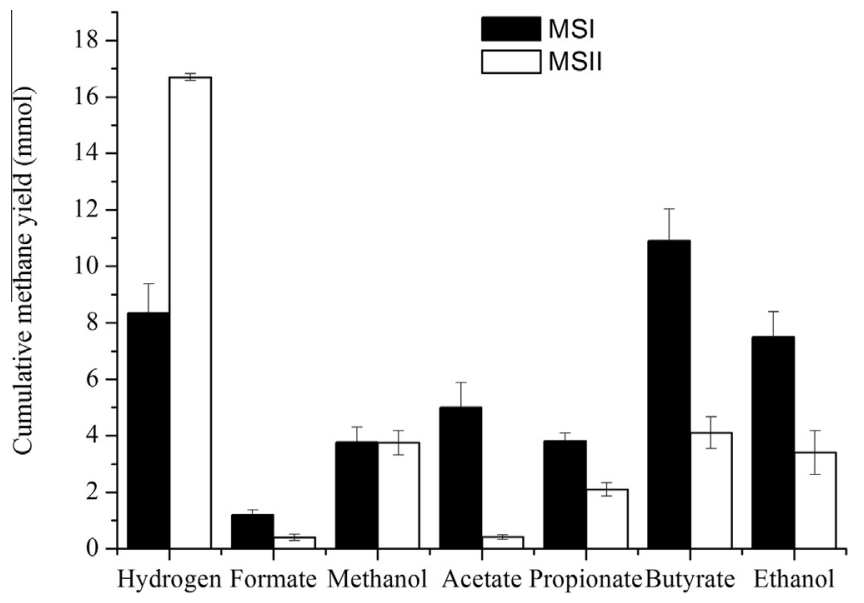

Fig. 3. Biomethane yield from different carbon resources using marine sediment as innocula after 30 days incubation.

Although the sodium concentration was very high in this study, the methane production was not affected obviously and even comparable to that obtained in previous reports at reduced salinity. It might be due to the adaption of marine sediment inocula to high sodium concentration.

\subsection{Methanogenetic activity evaluation of two marine sediment inocula using different carbon resources}

It was obvious that microbial consortium in both littoral and sublittoral marine sediments converted $M$. pyrifera to methane successfully. However, they showed quite different methanogenetic activity. In addition, although microbial consortium in both MSI and MSII set-ups could convert the seaweeds biomass to acetate and propionate efficiently (Table 3 ), their capacities in utilizing volatile fatty acids (VFA) seemed quite different. Both acetate and propionate could be fully consumed in a short period in MSIsetups, whereas, only partial of them were consumed until no obvious methane was produced in MSII set-ups. In order to get more information about the differences in the methanogenetic pathways, methanogenetic activities of the two inocula were evaluated using different carbon resources. As shown in Fig. 3, both the samples showed high activities using methanol and ethanol carbon resources. Comparing to MSII samples, MSI samples showed higher methane production activities using VFA and lower activities using $\mathrm{H}_{2} / \mathrm{CO}_{2}$. Generally, $\mathrm{H}_{2} / \mathrm{CO}_{2}$, formate, methanol, acetate, propionate, butyrate and ethanol constitute the bulk of the metabolic intermediate and can be used as substrates for methanogenesis. It was known that $\mathrm{H}_{2} / \mathrm{CO}_{2}$, formate and methanol can be directly transformed to methane by two different groups of methanogens, hydrogenotrophic and acetotrophic methanogens. Propionate and butyrate can only be degraded into acetate, $\mathrm{H}_{2} / \mathrm{CO}_{2}$ and/or formate and subsequently into methane (Glissmann and Conrad, 2000) 

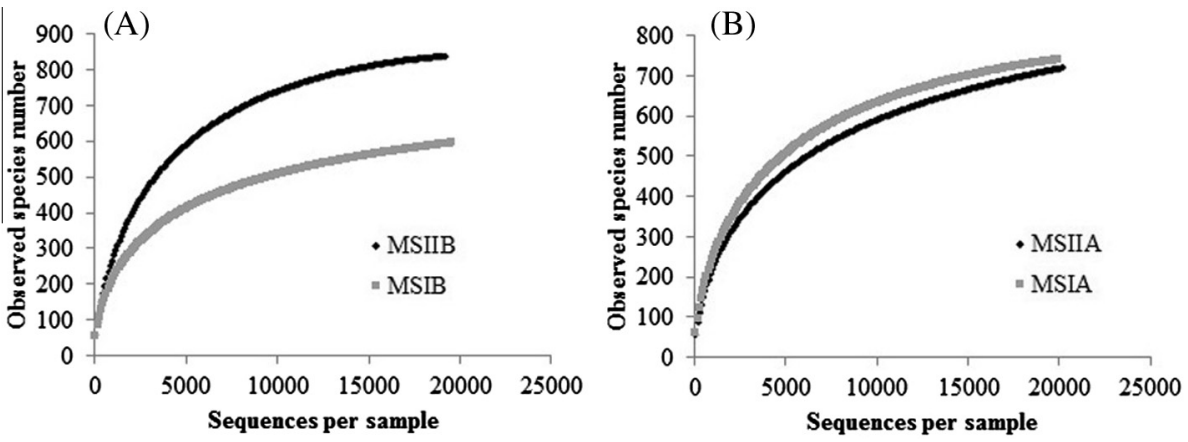

Fig. 4. Refraction curves of bacterial (A) and archaeal (B) 16srRNA gene clones from different set-ups.

k_Bacteria;p_Tenericutes;c__Mollicutes; 0 _ Acholeplasmatalesf

_Achol eplasm ataceae;g_ Acholeplasma;s

k_Bacteria;p_Proteobacteria;c_Betaproteobacteria;o_Burkhold eriales;f_C Comam onadaceae;g_Hylem onella;s_

k_Bacteria;p_Proteobacteria;c_Deltaproteobacteria; 0 Syntrop hobacteralesff_Syntrophaceae;g_Syntrophus;s

k_Bacteria;p_Proteobacteria;c_Betaproteobacteria;o_Rhodocy clales; f Rhodocyclaceae;g__ Dechloromonas

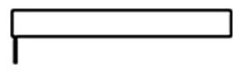

- MSIIB

k_Bacteria;p_Spirochaetes;c Spirochaetes;o_Spirochaetales; $f$ _Spirochaetaceae;g_treponem a;s_

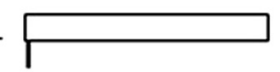

k_Bacteria; $p$ _Synergistetes;c_Synergistia; 0 _Synergistales; $f$ Dethiosulfovibrionaceae;g_HA $7 \overline{3} ; \mathrm{s}$

k_Bacteria;p_Proteobacteria;c_Deltaproteobacteria;o_Desulfo vibrionales;f_Desulfovibrionaceae;g_ Desulfovibrio;s

k_Bacteria;p_Firmicutes;c_Clostridia;o_Clostridiales;f_Syntr ophomonadaceae;g_Syntrophomonas;s_

k_Bacteria;p_Proteobacteria;c Deltaproteobacteria; 0 Desulfur omonadalesf $f$ _ G eobacteraceae;g_G eobacter

k_Bacteria;p_Firmicutes;c_Clostridia;o_Clostridiales;f_Rumi nococcaceae;g_Ruminococcus;s_

k_Bacteria;p_Firmicutes;c_Clostridia;o_Clostridiales;f_V eill onellaceae;g__Megasphaera;s_

$k$ Bacteria;p_Chloroflexi;c Anaerolineae;o Anaerolineales; $f$ _Anaerolinaceae;g_T78;s

k_Bacteria;p_Firmicutes;c_Clostridia;o_Clostridiales;f_Clost ridiaceae;g_Clostridium $; \mathrm{s}$
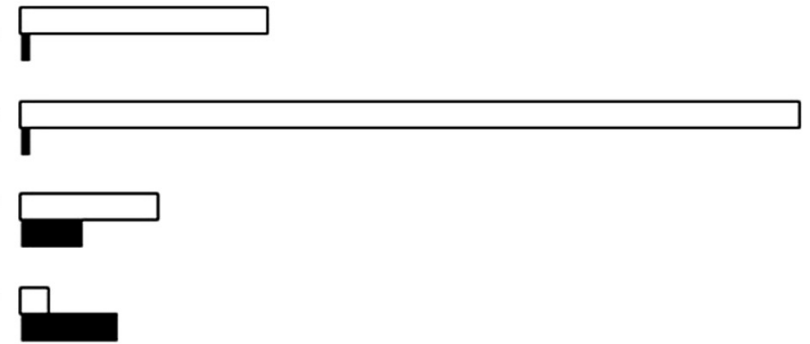

\section{L}
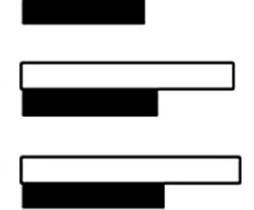

k_Bacteria;p_Firmicutes;c_Clostridia;o_Clostridiales;f_Rumi nococcaceae;g_Oscillospira;s_

k_Bacteria;p_Proteobacteria;c_Deltaproteobacteria; 0 Syntrop hobacterales $f$ __ Desulf obacteraceae;g_ Desulfococcus; $s$ -

k_Bacteria;p_Proteobacteria; __Alphaproteobacteria; 0 _Rhodos pirillales $f$ _Acetobacteraceae; $g$ _Acetobacter;s

k_Bacteria;p_Proteobacteria;c_Deltaproteobacteria; 0 _Desulfo

vibrionales;f_Desulfomicrobiaceae;g_ Desulfomicrobium;s

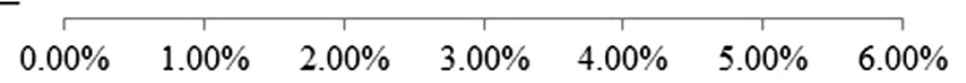

Relative abundance

Fig. 5. Bacterial composition of marine sediment innocula at the genus level. 
through syntrophic oxidation. Since the degradation processes of those substrates are usually thermodynamically unfavorable, they need the cooperation of fermentative syntrophic metabolizer and the methanogens. As to acetate and ethanol, both the direct transformation and syntrophic oxidation to methane could occur. Although the hydrogenotrophic methanogens in MSII set-ups showed very high activity, the acetotrophic methanogens or syntrophic acetate oxidation consortia seemed quite deficient. It might also lead to the deficiency of methanogenesis from propionate and butyrate, which coincided with the results in Table 3. Similar results were also found in some marine gas filed sediment in Bohai sea of China (Tian et al., 2014). Since acetate is generally the precursor of approximately two-thirds of the methane produced in anaerobic bioreactors (Jetten et al., 1992), the deficiency in utilizing acetate might result in great loss of methane. This might be the reason for higher methane yield obtained in MSI set-ups than in the MSII set-ups. Therefore, the littoral sediment with high methanogenetic activity from acetate was optimal in seawater anaerobic fermentation systems.

\subsection{Bacterial and archaeal community analysis in seawater anaerobic fermentation systems}

To get more information about the key bacterial and archaeal communities involved in the seawater anaerobic fermentation system, 16S rRNA sequence analysis was performed. Rarefaction curves (Fig. 4) analysis showed that the accumulation of phylotypes had reached clear saturation in all the samples. The coverage of bacterial and archaeal libraries was 95.7-97.0\%, indicating that the libraries were large enough for further analysis. It should be noted that almost $43.3 \%$ of the total bacterial gene tags and $93.4 \%$ 'of the archaeal ones were not classified to genera, which indicated that there were a lot of unclassified or uncultured marine microbial species and our knowledge of the microbes in marine environment was quite limited.

Within the domain Bacteria, 36 distinct phyla were detected. Proteobacteria (22.6\% in MSI and $35.4 \%$ in MS II), Firmicutes (26.7\% and 20.1\%) and Bacteroidetes (27.2\% and 32.2\%) represented the most abundant bacterial phyla in both MSI and MSII samples. As to the genera composition, different characters were demonstrated between MSI and MSII samples (Fig. 5). For MSI, the most abundant 10 genera were Desulfovibrio (5.6\%), HA73 (1.8\%), Treponema (1.7\%), Clostridium (1.6\%), Dechloromonas (1.6\%), T78 (1.56\%), Syntrophus (1.36\%), Hylemonella (0.9\%), Acholeplasma (0.7\%), respectively. For MSII, the most abundant 10 genera were Desulfomicrobium (3.4\%), Acetobacter (3.4\%), Desulfococcus (1.84\%), Oscillospira (1.1\%), Clostridium (1.0\%), T78 (1.0\%), Megasphaera (0.9\%), Ruminococcus (0.8\%), Geobacter (0.7\%), Syntrophomonas (0.4\%). Both samples were rich in Clostridium, T78 and Syntrophomonas, suggesting they might play irreplaceable roles in anaerobic degradation of seaweeds in seawater system. T78 was an uncultured candidate genus in Anaerolineaceae, which was described to be saccharolytic (Yamada et al., 2006). Microbial species in Clostridium usually produce mixtures of organic acids and alcohols from carbonhydrates or peptones. They may be saccharolytic, proteolytic, neither, or both. They may also metabolize carbohydrates, alcohols, amino acids, purines, steroids, or other organic compounds, indicating microbe in this genus contributed to hydrolysis and acidogenesis process. Microbial species in Syntrophomonas cells could b-oxidize saturated fatty acids

Table 4

VFA concentration in the digestate of MSI and MSII set-ups at different sampling time.

\begin{tabular}{|c|c|c|c|c|c|c|}
\hline \multirow[t]{2}{*}{ time (day) } & \multicolumn{3}{|l|}{ MSI (mg/l) } & \multicolumn{3}{|l|}{ MSII (mg/l) } \\
\hline & Acetate & Propionate & TVFA & Acetate & Propionate & TVFA \\
\hline 1 & $141.4 \pm 12.9$ & $63.2 \pm 13.6$ & $212.9 \pm 29.9$ & $139.2 \pm 12.0$ & $86.9 \pm 11.6$ & $244.4 \pm 28.2$ \\
\hline 14 & $251.6 \pm 43.2$ & $277.3 \pm 24.7$ & $595.7 \pm 82.2$ & $350.6 \pm 63.6$ & $357.2 \pm 19.2$ & $780.1 \pm 98.0$ \\
\hline${ }^{\mathrm{a}}$ Final & $0.8 \pm 0.3$ & $0.2 \pm 0.1$ & $1.50 \pm 0.8$ & $209.0 \pm 17.0$ & $226.7 \pm 12.0$ & $508.7 \pm 181.2$ \\
\hline
\end{tabular}

a The final samples were taken on the 30th day for MSI set-ups and on the 49th day for MS II set-ups.

Table 5

Metabolic characters of different bacterial genera involved in seawater system. The italic data belong to MSII set-ups.

\begin{tabular}{|c|c|c|c|c|c|c|c|c|c|}
\hline \multirow[t]{2}{*}{ Genus } & \multirow[t]{2}{*}{$\mathrm{O}_{2}$} & \multirow[t]{2}{*}{ Hydrolysis } & \multicolumn{5}{|l|}{ Substrate } & \multicolumn{2}{|c|}{ Product } \\
\hline & & & Carbonhydrate & Amino acid & Fatty acid & Aromatic compound & VFA & VFA & $\mathrm{H}_{2} \mathrm{~S}$ \\
\hline \multicolumn{10}{|l|}{ MSII-abundant } \\
\hline Desulfomicrobium (3.43\%) & - & & - & & & & + & + & + \\
\hline Acetobacter (3.35\%) & + & - & + & & & & & & - \\
\hline Desulfococcus (1.84\%) & - & & & & + & + & + & + & + \\
\hline \multicolumn{10}{|l|}{ Oscillospira $^{\mathrm{a}}(1.07 \%)$} \\
\hline Geobacter (0.69\%) & \pm & & & & & + & + & - & \pm \\
\hline Megasphaera (0.87\%) & - & - & + & & + & & & + & - \\
\hline Ruminococcus (0.83\%) & - & \pm & + & - & & & & + & \\
\hline \multicolumn{10}{|l|}{ MSI-abundant } \\
\hline Desulfovibrio (5.58\%) & - & & \pm & & & & + & + & + \\
\hline HA73 (1.76\%) & & & & + & & & & & - \\
\hline Treponema (1.73\%)) & \pm & & + & + & & & & & - \\
\hline Dechloromonas (1.56\%) & \pm & & - & & - & - & + & & - \\
\hline Syntrophus (1.30\%) & - & & & & $++^{\mathrm{b}}$ & + & - & + & - \\
\hline Hylemonella (0.86\%) & \pm & & - & + & + & & & & - \\
\hline Acholeplasma (0.69\%) & \pm & \pm & + & & & & & + & - \\
\hline \multicolumn{10}{|l|}{ Co-abundant } \\
\hline Syntrophomonas $(0.98 \%, 0.44 \%)$ & - & & - & - & $++^{\mathrm{b}}$ & & & + & - \\
\hline Clostridium $(1.57 \%, 1.01 \%)$ & - & \pm & \pm & \pm & & & & + & - \\
\hline $\mathrm{T} 78(1.51 \%, 0.97 \%)$ & & & + & & & & & & \\
\hline
\end{tabular}

a Growth in pure culture hasn't been reported.

b Substrates only utilized in co-culture with a hydrogenotroph. 
k_Archaea;p_Euryarchaeota;c_Methanomicrobia;o__ M ethanosarcinales;f__ Methanosarcinaceae;g__ Methanosarcin

a

k__Archaea; $p \_$Euryarchaeota; c__Methanomicrobia;o__ ethanosarcinales;___Methanosaetaceae;g__Methanosaeta;s_

k__Archaea; $p \_$Euryarchaeota; c__Methanomicrobia; o__ M ethanomicrobiales;f__. Methanoregulaceae;g__ Methanolinea ;s

k__Archaea;p_Euryarchaeota; c__ Methanococci;o__. Metha nococcales;f___ethanococcaceae;g__ Methanococcus;s

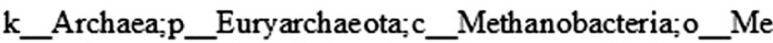
thanobacteriales; f__Methanobacteriaceae;g__Methanother mobacter;s_thermautotrophicus

k_Archaea;p_Euryarchaeota; c__Methanobacteria; o__Me thanobacterial es,f__. Methanobacteriaceae;g__Methanobacte rium

k_Archaea;p_Euryarchaeota;c__Halobacteria;o_Haloba cteriales;f_Halobacteriaceae;g__Haloarcula;s

k Archaea;p Crenarchaeota;c Thaumarchaeota;o Nit rososphaerales;f__Nitrososphaeraceae;g_Candidatus Nitrososphaera

k__Archaea;p_Crenarchaeota; c_Thaumarchaeota;o__Ce narchaeales;f_Cenarchaeaceae;g__ Nitrosopumilus

k__Archaea;p_Crenarchaeota; c_Thaumarchaeota;o__Ce narchaeales;f_Cenarchaeaceae;g_Cenarchaeum
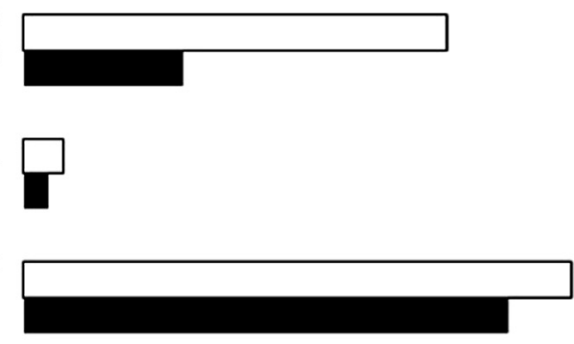

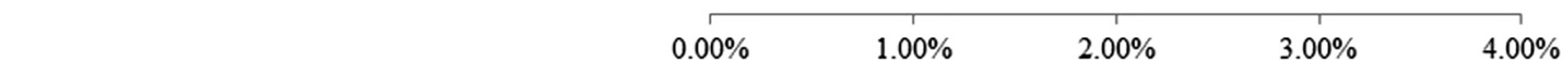

Relative abundance

Fig. 6. Archaeal composition of marine sediment innocula at the genus level.

anaerobically with protons serving as the electron acceptors in co-cultures with a hydrogenotroph and produce $\mathrm{H}_{2}$ and various VFAs. Moreover, both samples were abundant in microbes which can hydrolyze polymers or utilize carbonhydrates, fatty acids, aromatic compounds and VFAs (Table 5), indicating that they can convert $M$. pyrifera biomass to VFA efficiently. In comparison to MSII set-ups, MSI set-ups were abundant in amino acid utilizing bacteria (Table 4), indicating they might utilize algal protein more efficiently. Since the crude protein occupied almost $12.2 \%$ of the total solid (Table 1), the efficiency in degradation of protein and amino acid might greatly affect the final biogas production. It should be noted that both the samples were abundant in SRB. For MSI, Desulfovibrios represented the most abundant genus and occupied about 5.6\% of the total tags. However, Desulfomicrobium (3.4\%) and Desulfococcus (1.8\%) were the most abundant genus in MSII. These results agreed with the high $\mathrm{H}_{2} \mathrm{~S}$ content found in the biogas and further confirmed that sulfate reduction by SRB was one of the major problems that should be considered when applying anaerobic fermentation in seawater system.

Within the domain Archeae, two distinct phyla Crenarchaeota (35.0\% in MS I and 23.8\% in MS II) and Euryarchaeota (12.4\% and $17.2 \%)$ were detected. As to the class level, $3.7 \%$ of the total MSI tags were classified to methanobacteria, whereas only $0.9 \%$ of the total MSII tags were classified to methanobacteria. As to the tags classified to genera, results demonstrated that MSI samples contain much more genera and are more abundant than MSII samples (Fig. 6). For both samples, Methanobacterium represented the absolutely most abundant genus in Methanobacteria. Microbes in this genus were described as hydrogenotrophic methanogens. Low frequency of tags classified to Methanosarcina were also detected in both the two samples and microbes in this genus might utilize different substrates including $\mathrm{H}_{2} / \mathrm{CO}_{2}$, acetate, methanol, methylamine, dimethylsulfide and methanethiol. In addition, low frequency of tags classified to acetotrophic genera Methanosaeta were only found in MSI samples. It was reported that Methanosarcina and Methanosaeta (Methanothrix) were the only two genera of methanogenic archae known to use acetate as sole energy source. Methanosarcina could utilize several substrates with a high growth rate, but low affinity for acetate. However, Methanosaeta could only use acetate as sole carbon resource with a high affinity for acetate, but low growth rate. Methanosaeta showed a much lower minimum threshold for acetate utilization $(7-70 \mu \mathrm{M})$ than Methanosarcina (0.2-1.2 mM) (Jetten et al., 1992). So, it was thought Methanosaeta might contribute to the effective utilization of acetate in MSI set-ups (Table 3). Furthermore, compared with MSII samples, microbes classified to genera Methanolinea, Methanococcus and Methanothermobacter were also detected in low frequency in MSI samples. 
It should be noted that the hydrogenotrophic methanogens had an absolute dominance in distribution compared with the acetotrophic ones in both MSI and MSII samples. Taking the high methanogenetic activity from acetate by MSI (Fig. 3) into account, presence of active syntrophic acetate oxidation was suggested. It was ever reported that syntrophic acetate oxidation coupled to hydrogenotrophic methanogenesis was the dominating mechanism for methanogenesis from acetate in sludge containing high levels of salts, ammonium, and volatile fatty acids (Schnurer et al., 1999), maybe for the reason that acetotrophic methanogens were much more sensitive to the environment stress than hydrogenotrophic ones. It was thought the high levels of salts in this study might lead to methanogenesis through the syntrophic acetate oxidation.

So far, only six syntrophic acetate-oxidizing bacteria were purely cultured. They were, Clostridium ultunense strain BS (Schnurer et al., 1996), Thermacetogenium phaeum strain PB (Hattori et al., 2000), Syntrophaceticus schinkii (Westerholm et al., 2010), Tepidanaerobacter acetatoxydans (Westerholm et al., 2011) and Thermotoga lettingae strain TMO (Balk et al., 2002) and strain AOR (Lee and Zinder, 1988), respectively. However, none of the above species was detected in this study, indicating new syntrophic acetate-oxidizing bacteria species might exist in seawater system.

Schnurer et al (Schnurer et al., 1999) believed that the acetate degradation rate was lower (10-800 times) in biogas reactors in which methane was formed through syntrophic acetate oxidation than in biogas reactors where acetate was directly cleaved to methane and carbon dioxide. So, it was thought that optimizing of the inoculum by adding marine methanogens or consortia that can produce methane from acetate efficiently might further increase the biomethane production from seaweeds in seawater system.

\section{Conclusions}

In this study, marine sediments from littoral and sublittoral location were evaluated as inocula for methane production of $M$. pyrifera in seawater system. Littoral sediment with high methanogenetic activity from acetate was more suitable for thalassic anaerobic fermentation of seaweeds. High sulfate content was one of the major obstacles for application of thalassic biogas fermentation. Syntrophic acetate oxidation coupled to hydrogenotrophic methanogenesis might be the major methanogenetic pathway. These results first demonstrated that anaerobic fermentation of undiluted seaweeds in real seawater system could get as high methane yield as that obtained in terrestrial system with diluted seaweeds.

\section{Acknowledgements}

The authors appreciate professor Naihao Ye in Yellow Sea Fisheries Research Institute, Chinese Academy of Fisheries Science, for providing the $M$. pyrifera biomass. This paper was prepared under the auspices of the National High Technology Research and Development Program of China (863 Program) (2012AA052103).

\section{References}

Angenent, L.T., Sung, S.W., Raskin, L., 2002. Methanogenic population dynamics during startup of a full-scale anaerobic sequencing batch reactor treating swine waste. Water Res. 36 (18), 4648-4654.

Balk, M., Weijma, J., Stams, A.J.M., 2002. Thermotoga lettingae sp nov., a novel thermophilic, methanol-degrading bacterium isolated from a thermophilic anaerobic reactor. Int. J. Syst. Evol. Microbiol. 52, 1361-1368.

Chen, W.H., Han, S.K., Sung, S., 2003. Sodium inhibition of thermophilic methanogens. J. Environ. Eng.-ASCE 129 (6), 506-512.
Chen, Y., Cheng, J.J., Creamer, K.S., 2008. Inhibition of anaerobic digestion process: a review. Bioresour. Technol. 99 (10), 4044-4064.

Debowski, M., Zielinski, M., Grala, A., Dudek, M., 2013. Algae biomass as an alternative substrate in biogas production technologies-Review. Renew. Sustain. Energy Rev. 27, 596-604.

Demirbas, A., 2010. Use of algae as biofuel sources. Energy Convers. Manage. 51 (12), 2738-2749.

Ghosh, S., Klass, D.L., Chynoweth, D.P., 1981. Bioconversion of Macrocystis Pyrifera to methane. J. Chem. Tech. Biotechnol. 31, 791-807.

Glissmann, K., Conrad, R., 2000. Fermentation pattern of methanogenic degradation of rice straw in anoxic paddy soil. FEMS Microbiol. Ecol. 31 (2), 117-126.

Hattori, S., Kamagata, Y., Hanada, S., Shoun, H., 2000. Thermacetogenium phaeum gen. nov., sp nov., a strictly anaerobic, thermophilic, syntrophic acetateoxidizing bacterium. Int. J. Syst. Evol. Microbiol. 50, 1601-1609.

Hinks, J., Edwards, S., Sallis, P.J., Caldwell, G.S., 2013. The steady state anaerobic digestion of Laminaria hyperborea - effect of hydraulic residence on biogas production and bacterial community composition. Bioresour. Technol. 143, 221-230.

Huilinir, C., Quintriqueo, A., Antileo, C., Montalvo, S., 2014. Methane production from secondary paper and pulp sludge: effect of natural zeolite and modeling. Chem. Eng. J. 257, 131-137.

Jard, G., Jackowiak, D., Carrere, H., Delgenes, J.P., Torrijos, M., Steyer, J.P., Dumas, C. 2012. Batch and semi-continuous anaerobic digestion of Palmaria palmata: Comparison with Saccharina latissima and inhibition studies. Chem. Eng. J. 209, 513-519.

Jetten, M.S.M., Stams, A.J.M., Zehnder, A.J.B., 1992. Methanogenesis from Acetate - a Comparison of the Acetate Metabolism in Methanothrix-Soehngenii and Methanosarcina Spp. FEMS Microbiol. Lett. 88 (3-4), 181-197.

Laanbroek, H.J., Veldkamp, H., 1982. Microbial interactions in sediment communities. Philos. Trans. R. Soc. London Ser. B-Biol. Sci. 297 (1088), 533-550.

Lee, M.J., Zinder, S.H., 1988. Isolation and characterization of a thermophilic bacterium which oxidizes acetate in syntrophic association with a methanogen and which grows acetogenically on H2-Co2. Appl. Environ. Microbiol. 54 (1) 124-129.

Liu, J.W., Yang, H.M., Zhao, M.X., Zhang, X.H., 2014. Spatial distribution patterns of benthic microbial communities along the Pearl Estuary, China. Syst. Appl. Microbiol. 37 (8), 578-589.

Lovley, D.R., Dwyer, D.F., Klug, M.J., 1982. Kinetic-analysis of competition between sulfate reducers and methanogens for hydrogen in sediments. Appl. Environ. Microbiol. 43 (6), 1373-1379.

Magoc, T., Salzberg, S.L., 2011. FLASH: fast length adjustment of short reads to improve genome assemblies. Bioinformatics 27 (21), 2957-2963.

Marquez, G.P.B., Reichardt, W.T., Azanza, R.V., Klocke, M., Montano, M.N.E., 2013. Thalassic biogas production from sea wrack biomass using different microbial seeds: cow manure, marine sediment and sea wrack-associated microflora. Bioresour. Technol. 133, 612-617.

Medircio, S.N., Leao, V.A., Teixeira, M.C., 2007. Specific growth rate of sulfate reducing bacteria in the presence of manganese and cadmium. J. Hazard. Mater. 143 (1-2), 593-596.

Miura, T., Kita, A., Okamura, Y., Aki, T., Matsumura, Y., Tajima, T., Kato, J., Nakashimada, Y., 2014. Evaluation of marine sediments as microbial sources for methane production from brown algae under high salinity. Bioresour. Technol. 169, 362-366.

Oremland, R.S., Polcin, S., 1982. Methanogenesis and sulfate reduction competitive and noncompetitive substrates in estuarine sediments. Appl. Environ. Microbiol. 44 (6), 1270-1276.

Peiffer, J.A., Spor, A., Koren, O., Jin, Z., Tringe, S.G., Dangl, J.L., Buckler, E.S., Ley, R.E., 2013. Diversity and heritability of the maize rhizosphere microbiome under field conditions. Proc. Natl. Acad. Sci. U.S.A. 110 (16), 6548-6553.

Roesijadi, G., Jones, S.B., Snowden-Swan, L.J., Zhu, Y., 2010. Macroalgae as a Biomass Feedstock: a Preliminary Analysis. Pacific Northwest National Laboratory. Richland, WA.

Schnurer, A., Schink, B., Svensson, B.H., 1996. Clostridium ultunense sp nov, a mesophilic bacterium oxidizing acetate in syntrophic association with a hydrogenotrophic methanogenic bacterium. Int. J. Syst. Bacteriol. 46 (4), 1145-1152.

Schnurer, A., Zellner, G., Svensson, B.H., 1999. Mesophilic syntrophic acetate oxidation during methane formation in biogas reactors. FEMS Microbiol. Ecol. 29 (3), 249-261.

Schramm, W., Lehnberg, W., 1984. Mass-Culture of Brackish-Water-Adapted Seaweeds in Sewage-Enriched Seawater. 2. Fermentation for Biogas Production. Hydrobiologia, vol. 116(Sep), pp. 282-287.

Tian, Q., Wand, J., Fan, X.L., Luo, S.J., Guo, R.B., Qiu, Y.L., 2014. Methanogenic activity and methanogen diversity in marine gas field sediments. Environ. Sci. 35 (6) 2322-2327.

Ward, A.J., Lewis, D.M., Green, B., 2014. Anaerobic digestion of algae biomass: a review. Algal Research-Biomass Biofuels Bioproducts 5, 204-214.

Westerholm, M., Roos, S., Schnurer, A., 2010. Syntrophaceticus schinkii gen. nov., sp nov., an anaerobic, syntrophic acetate-oxidizing bacterium isolated from a mesophilic anaerobic filter. FEMS Microbiol. Lett. 309 (1), 100-104.

Westerholm, M., Roos, S., Schnurer, A., 2011. Tepidanaerobacter acetatoxydans sp. nov., an anaerobic, syntrophic acetate-oxidizing bacterium isolated from two ammonium-enriched mesophilic methanogenic processes. Syst. Appl Microbiol. 34 (4), 260-266.

Yamada, T., Sekiguchi, Y., Hanada, S., Imachi, H., Ohashi, A., Harada, H., Kamagata, Y., 2006. Anaerolinea thermolimosa sp nov., Levilinea saccharolytica gen. nov., sp 
nov and Leptolinea tardivitalis gen. nov., so. nov., novel filamentous anaerobes, and description of the new classes anaerolineae classis nov and Caldilineae classis nov in the bacterial phylum Chloroflexi. Int. J. Syst. Evol. Microbiol. 56, 1331-1340.
Yuan, X.Z., Shi, X.S., Zhang, P.D., Wei, Y.L., Guo, R.B., Wang, L.S., 2011. Anaerobic biohydrogen production from wheat stalk by mixed microflora: Kinetic model and particle size influence. Bioresour. Technol. 102 (19), 9007-9012. 